\title{
Bilateral lymphocytic alveolitis: a common reaction after unilateral thoracic irradiation
}

\author{
C. Martín*, S. Romero*, J. Sánchez-Payá**, B. Massutít, J.M. Arriero*, L. Hernández*
}

Bilateral lymphocytic alveolitis: a common reaction after unilateral thoracic irradiation. C. Martín, S. Romero, J. Sánchez-Payá, B. Massutí, J. M. Arriero, L. Hernández. C)ERS Journals Ltd 1999.

ABSTRACT: The main aim of the present study was to assess the early diagnostic value of bronchoalveolar lavage (BAL) in radiation-induced lung injury in patients with breast carcinoma.

Twenty-six females receiving postoperative radiotherapy for breast cancer were evaluated before and $0,15,30,60$, and 180 days after radiotherapy. History, physical examination, chest radiographs, and pulmonary function tests were obtained. BAL, including lymphocyte subsets analysis, was limited to the second evaluation after radiotherapy. A group of 21 healthy females were used as control. Findings after radiotherapy in asymptomatic patients were compared with findings in a group of patients with radiation pneumonitis.

Irradiated patients showed a significantly $(p<0.01)$ greater percentage $(29.5 \pm$ $15.7 \%)$ of BAL lymphocytes than controls $(6.2 \pm 3.3 \%)$. No statistical differences existed in BAL findings between the irradiated and unirradiated sides of the chest. Percentages of BAL lymphocytes did not differ significantly between patients who developed subsequent pneumonitis $(24.5 \pm 13.5 \%)$ and those who did not develop pneumonitis $(32.8 \pm 16.5 \%)$. Patients with pneumonitis at the time of BAL had significantly higher $(\mathrm{p}<0.05)$ alveolar CD4 subset cells $(24.8 \pm 10.2 \%)$ than asymptomatic patients $(15.2 \pm 8.9 \%)$. Maximal reductions in total lung capacity $(p<0.01)$, and residual volume $(\mathbf{p}<0.05)$ occurred 60 days after irradiation.

The early lymphocytic alveolitis induced by unilateral thoracic radiotherapy in most patients with breast cancer is always bilateral and does not predict the subsequent development of radiological evidence of pneumonitis. Eur Respir J 1999; 13: 727-732.

Thoracic radiotherapy is limited by its adverse effects on normal lung tissue [1-3]. The volume of irradiated lung, total radiation dose delivered, dose rate, fractionation applied, and the type of energy used all influence the subsequent appearance of radiation lung injury [4]. In up to $15 \%$ of patients, an early acute pneumonitis develops $6-12$ weeks after radiotherapy [5]. Lung changes induced by thoracic radiation were thought to be confined to only that part of the lung included in the radiation window [1-4]. However, ROBERTs et al. [6] have recently demonstrated that in most patients a lymphocytic alveolitis develops in both lung fields 4-6 weeks after strictly unilateral thoracic irradiation, and this was more pronounced in patients who developed pneumonitis. The mechanism whereby limited irradiation produces a severe generalized process has not been established $[6,7]$. The present prospective study was designed to confirm the existence of an early bilateral alveolitis following unilateral radiation and, since the presymptomatic finding of these changes could lead to a more effective management of radiation pneumonitis, to assess whether its presence or intensity could bear any relationship with the subsequent development of pneumonitis.

For editorial comments see page 715.
*Servicios de Neumología, **Epidemiología and ${ }^{+}$Oncología, Hospital General Universitario, Alicante, Spain.

Correspondence: C. Martín Av. Salamanca no. $34,6^{\circ} \mathrm{Izq}$ 03005 Alicante

Spain

Fax: 3465249759

Keywords: Bronchoalveolar lavage radiation pneumonitis radiotherapy

Received: January 301998

Accepted after revision September 251998

\section{Patients and methods}

The prospective study group consisted of 26 females referred for postoperative radiotherapy for breast cancer. The mean age was 50.9 \pm 11.2 yrs (range 29-68 yrs). Six patients were current or former smokers with a mean of $7 \pm 4.9$ pack-yrs.

Mastectomy, partial in 13 patients, and axillary dissection had been performed in all 26 patients.

Twenty-four premenopausal females received six cycles of adjuvant chemotherapy. In 12 patients, adriamycin, cyclophosphamide and 5-fluorouracil were given before radiotherapy, and in the 12 remaining patients, radiotherapy was given between the third and fourth cycles of cyclophosphamide, methotrexate, and 5-fluorouracil. Two postmenopausal patients received tamoxifen, $20 \mathrm{mg}$ daily.

All patients gave their informed consent for the study. Before radiotherapy, the following studies were performed: detailed medical history and examination, posteroanterior and lateral views of chest radiograph, and pulmonary function tests (PFT). All these procedures were repeated just after completing radiotherapy, and 15, 30, 60, and 180 days after. Bronchoalveolar lavage (BAL) was performed 15 days after the completion of radiotherapy. 


\section{Radiotherapy technique}

Eighteen patients received both a direct anterior field to the supraclavicular fossa angled to the ipsilateral axilla with the medial edge at midline, as well as medial-lateral opposed tangential beams for the chest wall or residual breast tissue. Eight patients received only the latter type of radiotherapy. Doses used were $45-50$ Gy in 1.8-2-Gy fractions to the supraclavicular fossa and to the breast. All treatments were given 5 days. week $^{-1}$ using a Cobalt-60 machine (Theratron 80; AELC, Ottawa, Canada).

\section{Bronchoalveolar lavage}

The BAL results from 21 healthy females, with a mean age of $20.2 \pm 3.6$ yrs were used as controls. Seventeen of these females were smokers of $2.4 \pm 1.0$ pack-yrs.

For comparative reasons, BAL results from three females with clinical radiation pneumonitis who were not included in the prospective study were also used. BAL was carried out using an Olympus fibreoptic instrument (Olympus Optical Company, Hamburg, Germany) under local anaesthesia. The bronchoscope was wedged into the anterior segment of both upper lobes, beginning with the unirradiated one. In the five patients who presented with radiation infiltrates, the BAL samples were taken from the more affected segment. Room-temperature normal saline $(150 \mathrm{~mL})$ was instilled into each segment, in three $50-\mathrm{mL}$ aliquots, each aspirated gently with syringe after instillation. The first aliquot was exclusively used for bacteriological studies, including Mycobacterium tuberculosis and Pneumocystis carinii. The fluid was collected in a siliconized vessel and immediately transported to the laboratory.

The fluid was homogenized with a Pasteur pipette, and a sample of the lavage was counted in a Neubauer chamber. Cell counts were expressed as cells per $100 \mathrm{~mL}$. The analysis of differential cell counts and lymphocyte subsets of BAL cells was performed using a flow cytometer (Cytoron Absolute Ortho; Ortho Diagnostic System, New Jersey, USA). BAL cells were washed with phosphatebuffered saline (PBS) and centrifuged for $10 \mathrm{~min}$ at $600 \times g$. An aliquot $(100 \mu \mathrm{L})$ at $5 \times 10^{6} \mathrm{cells} \cdot \mathrm{mL}^{-1}$, was incubated with $10 \mathrm{~mL}$ of fluorochrome-conjugated monoclonal antibody for $20 \mathrm{~min}$ at $4{ }^{\circ} \mathrm{C}$, and gating was checked using a flow cytometer. The following antibodies were used: CD3, CD4, CD8, CD20, CD56, CD36, CD15, CD$11 \mathrm{~b}$ and human leukocyte antigen (HLA)-DR (Ortho Diagnostic System, Neckargemünd, Germany). A lymphocyte percentage $>15 \%$ was considered indicative of alveolar lymphocytosis $[8,9]$.

\section{Pulmonary function tests}

The initial evaluation was performed several weeks after mastectomy when the scar had healed, and incisional pain was no longer present. The following PFT were performed using a Master-Lab Jaeger equipment (Würzburg, Germany): maximum expiratory flow-volume curve, including forced vital capacity (FVC), forced expired volume in one second (FEV1), and the FEV1/FVC ratio; single breath diffusing capacity, and lung volume studies, including total lung capacity (TLC) and residual volume (RV). Each PFT was expressed as a percentage of predicted values based on age, sex, race and height according to European Community for Coal and Steel reference values [10].

\section{Chest radiographs}

Posteroanterior and lateral radiographs of the chest were evaluated independently by three observers (C. Martín, S. Romero, L. Hernández), and agreement of at least two was required.

Any new interstitial or alveolar infiltrate with or without simultaneous loss in lung volume in the absence of another evident cause was considered indicative of radiation pneumonitis.

\section{Statistical analysis}

To compare pulmonary function parameters between intervals, the Wilcoxon rank test for paired data in the SPSS statistical package (SPSS Inc., Chicago, IL, USA) was used. The Mann-Whitney U-test was used to compare changes in pulmonary function between groups.

To compare BAL findings between groups, the Student's t-test for unpaired data was used. Differences in BAL between both lungs were assessed by the paired Student's t-test. Values of $\mathrm{p}<0.05$ were considered as significant.

\section{Results}

Eight patients (31\%) developed radiological signs of pneumonitis 15-90 days after completing radiotherapy. The infiltrates, interstitial or alveolointerstitial, were always limited to the upper lobes of the irradiated side. Signs of volume loss were evident in two patients. Together with the radiographic signs, four patients presented symptoms consisting of cough (four), dyspnoea (three) and fever (one). Four patients remained asymptomatic. No patient developed progressive symptomatic radiation fibrosis.

Patients who developed radiation pneumonitis were younger $(46.8 \pm 10.9 \mathrm{yrs})$ than patients without pneumonitis $(52.6 \pm 11.7 \mathrm{yrs})$. Seven out of eight patients who developed radiation pneumonitis had received direct irradiation.

\section{$B A L$ results}

Differences in mean BAL data between patients and controls are given in table 1 . When compared with healthy females, total lavage cell numbers, the percentages of neutrophils, lymphocytes, and CD4 and CD8 lymphocyte subsets were significantly higher in patients (table 1).

In 22 of 26 patients $(85 \%)$, radiotherapy induced an alveolar lymphocytosis. Alveolar lymphocytosis was always bilateral and of a similar intensity in the irradiated $(29.5 \pm 15.7 \%$ lymphocytes) and unirradiated lung (29.1 \pm $13.6 \%$ lymphocytes) (table 2 ).

Two patients presented with radiographic pneumonitis when the BAL was carried out. The BAL data from these patients, together with those of the three patients not prospectively studied, are shown in table 3, and compared with those of the 24 patients without evident pneumonitis in table 4 . The mean age of the five patients with radiation pneumonitis was $51.2 \pm 5.3$ yrs, and all were nonsmokers and had been treated with adjuvant cyclophosphamide, methotrexate and 5-fluorouracil. 
Table 1. - Bronchoalveolar lavage findings: differences between patients (irradiated side) and healthy female controls

\begin{tabular}{lccc}
\hline & $\begin{array}{c}\text { Patients } \\
\mathrm{n}=26\end{array}$ & $\begin{array}{c}\text { Controls } \\
\mathrm{n}=21\end{array}$ & $\mathrm{p}$-value \\
\hline Volume mL & $66.9 \pm 12.7$ & $80.8 \pm 12.4$ & 0.01 \\
Total cells* & $34.5 \pm 11.1$ & $23.7 \pm 14.6$ & 0.001 \\
Macrophages \% & $61.5 \pm 19.5$ & $91.9 \pm 4.1$ & 0.001 \\
Neutrophils \% & $4.6 \pm 3.6$ & $1.5 \pm 1.7$ & 0.001 \\
T-lymphocytes \% & $29.5 \pm 15.7$ & $6.2 \pm 3.3$ & 0.001 \\
CD4 \% & $15.1 \pm 8.6$ & $3.1 \pm 1.5$ & 0.001 \\
CD8 \% & $12.9 \pm 8.2$ & $3.2 \pm 1.9$ & 0.001 \\
CD4/CD8 ratio & $1.7 \pm 1.3$ & $1.1 \pm 0.4$ & 0.05 \\
\hline
\end{tabular}

Results are expressed as mean \pm SD. *: expressed as $10^{6}$ cells $\cdot 100$ $\mathrm{mL}$ lavage fluid $^{-1}$.

No significant differences between lungs were found in the lavage material of patients with pneumonitis (table 3 ).

Patients with pneumonitis at the time of BAL had a higher percentage of CD3 lymphocytes $(39.0 \pm 8.0 \%)$ than patients without pneumonitis $(30.0 \pm 16.4 \%)$ and a significantly higher percentage $(\mathrm{p}<0.05)$ of CD4 (table 4).

Early inflammatory lymphocytic alveolitis in both irradiated $(21.3 \pm 14.1$ versus $32.8 \pm 16.5 \%$ lymphocytes $)$ and unirradiated sides $(25.7 \pm 16.2$ versus $30.8 \pm 13.6 \%$ lymphocytes), was of a similar degree in patients who ultimately, but not at the time of BAL, developed pneumonitis than in those who did not develop pneumonitis (tables 5 and 6). Two out of the six patients who later developed pneumonitis did not present with lymphocytic alveolitis.

No observable effect was found for surgical lumpectomy versus mastectomy or for methotrexate versus adriamycin on the percentage of alveolar lymphocytes, although the total number of cells was significantly lower in patients treated with methotrexate or by lumpectomy (data not shown). The two patients who did not receive chemotherapy developed bilateral alveolar lymphocytosis (40 and $27 \%$ on the irradiated side, and 37 and $38 \%$ on the unirradiated side).

The bacteriological studies were always negative.

\section{Lung function}

Maximal and significant reductions in TLC $(p<0.01)$, and RV $(\mathrm{p}<0.05)$, with respect to basal values, occurred 60 days after radiotherapy. A significant recovery $(\mathrm{p}<0.04), 4$

Table 2. - Bronchoalveolar lavage findings: comparison between the irradiated and unirradiated sides of the chest in 26 patients

\begin{tabular}{lccc}
\hline & Irradiated & Unirradiated & p-value \\
\hline Volume mL & $66.9 \pm 12.7$ & $62.6 \pm 16.7$ & 0.28 \\
Total cells* & $34.5 \pm 11.1$ & $36.3 \pm 12.4$ & 0.59 \\
Macrophages \% & $61.5 \pm 19.5$ & $62.2 \pm 18.2$ & 0.67 \\
Neutrophils \% & $4.6 \pm 3.6$ & $4.8 \pm 4.0$ & 0.64 \\
T-lymphocytes \% & $29.5 \pm 15.7$ & $29.1 \pm 13.6$ & 0.79 \\
CD4 \% & $15.1 \pm 8.6$ & $15.0 \pm 7.8$ & 0.96 \\
CD8 \% & $12.9 \pm 8.2$ & $13.0 \pm 7.7$ & 0.89 \\
CD4/CD8 ratio & $1.7 \pm 1.3$ & $1.6 \pm 1.2$ & 0.064 \\
\hline
\end{tabular}

Results are expressed as mean \pm SD. *: expressed as $10^{6}$ cells $\cdot 100$ $\mathrm{mL}$ lavage fluid ${ }^{-1}$.
Table 3. - Bronchoalveolar lavage findings: comparison between the irradiated and unirradiated sides of the chest in five patients with radiation pneumonitis

\begin{tabular}{lccc}
\hline & Irradiated & Unirradiated & p-value \\
\hline Volume mL & $72.2 \pm 8.4$ & $69.6 \pm 19.7$ & 0.77 \\
Total cells* & $34.1 \pm 9.6$ & $34.0 \pm 10.0$ & 0.98 \\
Macrophages \% & $50.0 \pm 8.6$ & $56.8 \pm 9.3$ & 0.052 \\
Neutrophils \% & $6.6 \pm 6.9$ & $4.6 \pm 2.7$ & 0.46 \\
T-lymphocytes \% & $39.0 \pm 8.0$ & $34.6 \pm 10.4$ & 0.08 \\
CD4 \% & $24.8 \pm 10.2$ & $25.2 \pm 13.2$ & 0.36 \\
CD8 \% & $16.2 \pm 6.8$ & $12.0 \pm 5.2$ & 0.28 \\
CD4/CD8 ratio & $2.2 \pm 1.8$ & $2.8 \pm 1.9$ & 0.38 \\
\hline
\end{tabular}

Results are expressed as mean \pm SD. *: expressed as $10^{6}$ cells $\cdot 100$ $\mathrm{mL}$ lavage fluid $^{-1}$.

months later, was only evident in RV (table 7). The reduction was not more pronounced in those patients who developed pneumonitis.

\section{Discussion}

There is usually a delay, ranging $1-3$ months, from the completion of radiotherapy to the development of acute pneumonitis [3, 11]. Although symptoms may develop before apparent radiographic change, the number of patients who show radiological abnormalities is significantly higher than the number of patients with symptoms [3]. It was for this higher sensitivity that the radiographic changes were considered in this study as the markers of acute lung injury. Compared with the routine chest radiographs, computed tomography (CT) has been considered to be more sensitive for radiation-induced lung injury in that changes may be observed as early as 4 weeks post-irradiation [5]. Because, in the present study, two patients showed radiographical evidence of pneumonitis only 2 weeks postirradiation, such an early detection does not, however seem exclusive to CT.

The development of lymphocytic alveolitis in the lung exposed to radiation in patients with lung as well as breast cancer has been previously demonstrated [12-15]. The first well-documented study of bilateral lymphocytic alveolitis after unilateral radiotherapy in patients with breast cancer was published by GIBSON et al. [7] in 1988, and more recently, they have expanded upon their prior investigation

Table 4. - Differences in bronchoalveolar lavage (BAL) findings between five patients with radiation pneumonitis and 24 patients without any evidence of pneumonitis at the moment of BAL (irradiated side)

\begin{tabular}{lccc}
\hline & $\begin{array}{c}\text { With } \\
\text { pneumonitis }\end{array}$ & $\begin{array}{c}\text { Without } \\
\text { pneumonitis }\end{array}$ & p-value \\
\hline Volume mL & $72.2 \pm 8.4$ & $66.5 \pm 13.1$ & 0.36 \\
Total cells* & $34.1 \pm 9.6$ & $34.9 \pm 10.5$ & 0.62 \\
Macrophages \% & $50.0 \pm 8.6$ & $61.5 \pm 19.9$ & 0.22 \\
Neutrophils \% & $6.6 \pm 6.9$ & $4.8 \pm 3.6$ & 0.61 \\
T-lymphocytes \% & $39.0 \pm 8.0$ & $30.0 \pm 16.4$ & 0.24 \\
CD4 \% & $24.8 \pm 10.2$ & $15.2 \pm 8.9$ & 0.04 \\
CD8 \% & $16.2 \pm 6.8$ & $12.3 \pm 8.0$ & 0.32 \\
CD4/CD8 ratio & $2.2 \pm 1.8$ & $1.8 \pm 1.3$ & 0.56 \\
\hline
\end{tabular}

Results are expressed as mean \pm SD. *: expressed as $10^{6}$ cells $\cdot 100$ mL lavage fluid $^{-1}$. 
Table 5. - Bronchoalveolar lavage findings (irradiated side): differences between six patients ultimately developing radiation pneumonitis (DRP) and 18 patients without any evidence of pneumonitis (NDRP)

\begin{tabular}{lccc}
\hline & DRP & NDRP & p-value \\
\hline Volume mL & $67.7 \pm 11.6$ & $66.1 \pm 13.8$ & 0.86 \\
Total cells* & $39.0 \pm 12.5$ & $33.7 \pm 11.6$ & 0.55 \\
Macrophages \% & $73.5 \pm 17.3$ & $57.4 \pm 19.5$ & 0.12 \\
Neutrophils \% & $3.5 \pm 2.1$ & $5.2 \pm 4.0$ & 0.44 \\
T-lymphocytes \% & $21.3 \pm 14.1$ & $32.8 \pm 16.5$ & 0.12 \\
CD4 \% & $13.5 \pm 9.3$ & $15.7 \pm 9.0$ & 0.62 \\
CD8 \% & $7.8 \pm 5.9$ & $13.9 \pm 8.3$ & 0.11 \\
CD4/CD8 ratio & $1.9 \pm 0.7$ & $1.7 \pm 1.4$ & 0.29 \\
\hline
\end{tabular}

Results are expressed as mean \pm SD. *: expressed as $10^{6}$ cells $\cdot 100$ $\mathrm{mL}$ lavage fluid $^{-1}$.

[6], confirming the previous results. Although the lymphocytic alveolitis was more intense in patients who developed clinical pneumonitis, a similar but less intense reaction was also seen in the lavage of asymptomatic patients who received radiotherapy.

Despite differences in BAL technique, with respect to these latter studies $[6,7]$, the present study confirms their results. The cytocentrifuge preparations used herein, compared with millipore filter preparations, may underestimate the percentage of lymphocytes in the BAL fluid $[16,17]$. However, due to its relative simplicity, it has been common practice to use the cytocentrifuge method for quantifying BAL cells in most laboratories [8, 9, 18]. Although in the patients studied by RoBERTs et al. [6], using millipore filter preparations, the percentages and absolute number of alveolar lymphocytes were much higher than in the patients in the present study, the differences with controls in both studies were equivalent, allowing similar conclusions to be drawn.

The present study demonstrates that the lymphocytic alveolitis occurs within 15 days after completion of radiotherapy in a proportion of patients almost identical to that found by RoBERTS et al. [6] 2-4 weeks post-irradiation, and as in their patients, the intensity of the lymphocytic alveolitis was higher in those with pneumonitis. In the present study these differences were only significant in the CD4 subset, but this higher percentage of CD4 cells, together with evident overactivation of these cells, was also found by ROBERTs et al. [6] in the only patient in whom lymphocyte subsets were determined.

Table 6. - Bronchoalveolar lavage findings (unirradiated side): differences between six patients ultimately developing radiation pneumonitis (DRP) and 18 patients without any evidence of pneumonitis (NDRP)

\begin{tabular}{lccc}
\hline & DRP & NDRP & p-value \\
\hline Volume mL & $68.5 \pm 12.2$ & $59.0 \pm 17.7$ & 0.23 \\
Total cells* & $34.4 \pm 8.3$ & $38.2 \pm 13.3$ & 0.84 \\
Macrophages \% & $69.2 \pm 19.4$ & $58.9 \pm 18.4$ & 0.37 \\
Neutrophils \% & $2.8 \pm 1.8$ & $5.6 \pm 4.4$ & 0.15 \\
T-lymphocytes \% & $25.7 \pm 16.2$ & $30.8 \pm 13.6$ & 0.44 \\
CD4 \% & $14.7 \pm 9.3$ & $15.8 \pm 7.8$ & 0.97 \\
CD8 \% & $11.0 \pm 8.0$ & $13.5 \pm 7.9$ & 0.46 \\
CD4/CD8 ratio & $1.5 \pm 0.6$ & $1.6 \pm 1.4$ & 0.53 \\
\hline
\end{tabular}

Results are expressed as mean \pm SD. *: expressed as $10^{6}$ cells $\cdot 100$ $\mathrm{mL}_{\text {lavage }}$ fluid $^{-1}$.
Microcapillary vascular damage together with damage to type I and II pneumocytes results in ischaemic tissue injury, altered surfactant production, atelectasis and secondary vascular atrophy within the radiation treatment window $[11,19]$. These changes result from the interaction of radiotherapy with genetic or environmental factors, such as concurrent therapy [20], degree of lymphoid irradiation [21], and age [22]. RoBERTs et al. [6] postulated that because this mechanism cannot adequately explain either the degree of respiratory distress after the irradiation of a relatively small volume of lung tissue, or the resolution of symptoms with time without significant sequelae in most patients, another mechanism, possibly a lymphocyticmediated hypersensitivity reaction, could participate in the process. It is possible that direct tissue damage from radiotherapy, known to cause antigen release [3], produces sensitization of autoreactive lymphocyte clones, which then migrate to the lung and react with pulmonary tissues.

Scattering of irradiation outside the intended radiation field may occur. However, the dose that the unirradiated lung would receive is usually well below the tolerance dose for lung tissue and the dose received by the irradiated lung. Although lung infiltrates outside the radiation field may occur [23-25], most patients, as in the present study, show involvement confined to the irradiation window. Thus, scattering of irradiation appears an unlikely explanation for the lymphocytic alveolitis demonstrated in BAL of the contralateral lung, which is of similar intensity to that seen in the irradiated lung.

In the present study patients were not used as their own control, and this does not rule out the presence of a previous lymphocytic alveolitis. Methotrexate pneumonitis [26] or toxicity from another chemotherapeutic agent [27], or allergic alveolitis related to a humidifier system or to another antigen in the local environment [28] could be associated with similar findings in the BAL. However, patients receiving methotrexate without evidence of pulmonary toxicity had a normal percentage of alveolar lymphocytes, and no patient in this series presented any distinctive signs related to methotrexate pneumonitis $[26$, 29]. Furthermore, 12 patients, included herein, free from chemotherapy with methotrexate, also demostrated bilateral alveolar lymphocytosis. Also, against the possible influence of chemotherapy is the fact that two patients in the present study and 10 patients in the study by ROBERTS et al. [6], who did not receive chemotherapy, developed bilateral alveolar lymphocytosis. A selective allergic alveolitis was not clinically evident in any patient, and was considered unlikely in females who, while in hospital, were not exposed to any environmental agents known to induce lung disorders, and were later treated as outpatients.

The present study was designed to evaluate whether an early inflammatory alveolitis was associated with the subsequent development of radiation pneumonitis. Contrary to the study by LAFFITE et al. [12], which showed a significantly more intense lymphocytic alveolitis in those patients who later on developed pneumonitis, it was not possible from the initial intensity of the alveolitis to anticipate the subsequent course of the disease. It is difficult to assess the methodological differences responsible for this interstudy discrepancy because to our knowledge, the study by LAFFITE et al. [12] was only published as an abstract. However, chronological differences could explain the differences in the results from both studies. In fact, a 
Table 7. - Changes in pulmonary function tests after radiotherapy

\begin{tabular}{lccrrr}
\hline Time & FVC $\%$ & TLC $\%$ & RV $\%$ & DL,CO \% & $P$ PA-a, $\mathrm{O}_{2}$ \\
\hline BRT & $108(99-116)$ & $102(92-111)$ & $96(87-115)$ & $97(87-107)$ & $11(6-18)$ \\
ART & $108(99-119)$ & $105(96-113)$ & $101(89-113)$ & $98(89-105)$ & $13(6-18)$ \\
Day 14 & $111(100-118)$ & $103(92-112)$ & $103(88-112)$ & $97(87-105)$ & $7(4-14)$ \\
Day 30 & $111(97-118)$ & $106(100-110)$ & $100(84-115)$ & $97(85-106)$ & $8(4-12)$ \\
Day 60 & $110(92-120)$ & $96(90-105)$ & $90(73-106)$ & $94(88-101)$ & $11(4-18)$ \\
p-value* & 0.36 & 0.007 & 0.019 & 0.73 & 0.67 \\
Day 180 & $106(92-121)$ & $101(86-113)$ & $92(84-108)$ & $95(88-108)$ & $10(4-17)$ \\
p-value** & 0.64 & 0.23 & 0.035 & 0.51 & 0.18 \\
\hline
\end{tabular}

Results are expressed as the median (25-75th percentiles). BRT: before radiotherapy; ART: after radiotherapy; FVC: forced vital capacity; TLC: total lung capacity; RV: residual volume; $D$ L,CO: diffusing capacity of the lung for carbon monoxide; $P$ A-a, $\mathrm{O}_{2}$ : alveolararterial tension difference for oxygen; *: denotes the difference between values before radiotherapy and values 60 days after its completion; **: denotes the difference between values 60 and 180 days after the completion of radiotherapy.

heralding alveolitis 4 weeks post-irradiation, as the results of LAFFITE et al. [12] seem to indicate, but not evident only 2 weeks post-irradiation, cannot be ruled out. However, a lymphocytic alveolitis has been previously shown in patients with Crohn's disease [30, 31], dairy farmers [32, 33] and individuals exposed to asbestos [34]. In all of these, as in the present population, lavage lymphocytosis per se did not predict lung disease, deterioration of pulmonary function, or radiological changes over the time span studied.

In radiation pulmonary lung injury, PFT are typical for an alveolar-based disease, with a decrease in lung volumes and diffusing capacity usually being detected within 11 weeks after the completion of radiotherapy [35]. In this limited series of patients with irradiated breast cancer, significant changes were revealed by TLC and RV. The maximal decrease was 60 days after completion of radiotherapy and occurred, as reported previously [36-38], without any apparent relationship with radiographic changes. These findings suggest that the reduction in pulmonary volume depends more on the diffuse lymphocytic alveolitis than on the extension of the localized lung damage.

In summary, the results of the present study confirm that in most patients, an early lymphocytic alveolitis develops in both lung fields after strictly unilateral thoracic irradiation. However, the early cytological changes in bronchoalveolar lavage do not add any valuable information to that provided by routine chest radiographs for the better management of radiation pneumonitis.

\section{References}

1. Bate D, Guttman RJ. Changes in lung and pleura following two-million-volt therapy for carcinoma of the breast. Radiology 1957; 69: 372-382.

2. Fleming JAC, Filbee JIF, Wiernik G. Sequelae to radical irradiation in carcinoma of the breast. An inquiry into the incidence of certain radiation injuries. Br J Radiol 1961; 34: 713-719.

3. Gross NJ. Pulmonary effects of radiation therapy. Ann Intern Med 1977; 86: 81-92.

4. Jennings FL, Arden A. Development of radiation pneumonitis. Time and dose factors. Arch Pathol 1962; 74: 351-360.
5. Davis SD, Yankelevitz DF, Henschke CI. Radiation effects on the lung: clinical features, pathology, and imaging findings. Am J Roentgenol 1992; 159: 1157-1164.

6. Roberts CM, Foulcher E, Zaunders JJ, et al. Radiation pneumonitis: a possible lymphocyte-mediated hypersensitivity reaction. Ann Intern Med 1993; 118: 696-700.

7. Gibson PG, Bryant DH, Morgan GW, et al. Radiationinduced lung injury: a hypersensitivity pneumonitis? Ann Intern Med 1988; 109: 288-291.

8. American Thoracic Society. Clinical role of bronchoalveolar lavage in adults with pulmonary disease. Am Rev Respir Dis 1990; 142: 481-486.

9. Cherniack RM. Bronchoalveolar lavage constituents in healthy individuals, idiopathic pulmonary fibrosis and selected comparisons groups. Am Rev Respir Dis 1990; 141 (Suppl): 166-202.

10. Quanjer PH, ed. Standardized lung function testing. Report of working party for "Standardization of lung function tests". European Community for Coal and Steel, Luxembourg. Bull Eur Respir 1983; 19 (Suppl 52): 1-95.

11. Gross NJ. The pathogenesis of radiation-induced lung damage. Lung 1981; 159: 115-125.

12. Lafitte JJ, Guiselin M, Gosselin B, Aerts A, Tonnel AB, Voisin C. Diagnostic and predictive value of bronchoalveolar lavage (BAL) in lung injury after radiotherapy. Am Rev Respir Dis 1986; 133: A287.

13. Tonnel AB, Voisin C, Lafitte JJ, Ramon PH, Aerts C. Variations des populations cellulaires recueillies par lavage bronchoalveolaire en function de la thopographie des lesións et l'etage explore. INSERM 1979; 84: 271-280.

14. Cordier JF, Mornex JF, Lasne Y, et al. Bronchoalveolar lavage in radiation pneumonitis. Bull Eur Physiopathol Respir 1984; 20: 369-374.

15. Maasilta P, Halman M, Taskinen E, Kivisanri L, Mattson $\mathrm{K}$. Bronchoalveolar lavage fluid findings following radiotherapy for non-small cell lung cancer. Int J Radiat Oncol Biol Phys 1993; 26: 117-123.

16. Saltini C, Hance AJ, Ferrans VJ, Basset F, Bitterman PB, Crystal RG. Accurate quantification of cells recovered by bronchoalveolar lavage. Am Rev Respir Dis 1984; 130: 650-658.

17. Breit SN. Quantifying lymphocytes in bronchoalveolar lavage fluid. Ann Intern Med 1993; 119: 1051.

18. Klech H, Polh W. Technical recommendations and guidelines for bronchoalveolar lavage. Eur Respir J 1990; 2: 561-585. 
19. Coggle JE, Lambert BE, Moores SR. Radiation effects in the lung. Environ Hlth Perspect 1986; 70: 261-291.

20. Phillips TL, Whara MD, Margolis LW. Modification of radiation injury to normal tissues by chemotherapeutic agents. Cancer 1975; 35: 1678-1684.

21. Newman GH, Rees JG, Jones RSJ, Grove EA, Preece AW. Changes in helper and suppressor T lymphocytes following radiotherapy for breast cancer. Clin Radiology 1987; 38: 191-193.

22. Koga K, Kusumoto S, Watanabe K, Nishikawa K, Harada $\mathrm{K}$, Ebihara H. Age, factor relevant to the development of radiation pneumonitis in radiotherapy of lung cancer? Int J Radiat Oncol Biol Phys 1988; 14: 367-371.

23. Smith JC. Radiation pneumonitis. Case report of bilateral reaction after unilateral irradiation. Am Rev Respir Dis 1964; 89: 264-269.

24. Crestani B, Kambouchner M, Soler P, et al. Migratory bronchiolitis obliterans organizing pneumonia after unilateral radiation therapy for breast carcinoma. Eur Respir $J$ 1995; 8: 318-321.

25. Bayle JY, Nesme P, Béjui-Thivolet F, Loire R, Guérin JC, Cordier JF. Migratory organizing pneumonitis "primed" by radiation therapy. Eur Respir $J$ 1995; 8: 322-326.

26. White DA, Rankcin JA, Stover DE, Gallene RA, Gupta S. Methotrexate pneumonitis. Am Rev Respir Dis 1989; 139: $18-21$.

27. Akoun GM, Cadranel JL, Milleron BJ, D'Ortho MF, Mayaud CM. Bronchoalveolar lavage cell data in 19 patients with drug-associated pneumonitis (except Amiodarone). Chest 1991; 99: 98-104.

28. Costabel V, Bross KJ, Marxen J, Mattys H. T-lymphocytosis in bronchoalveolar lavage fluid of hypersensitivity pneumonitis. Chest 1984 ; 85: 514-518.

29. Akoun GM, Mayaud CM, Toboul JL, Denis MF, Milleron BJ, Perrot JY. Use of bronchoalveolar lavage in the ev- aluation of methotrexate lung disease. Thorax 1987; 42: 652-655.

30. Wallaert B, Colombel JF, Tonnel AB, et al. Evidence of lymphocyte alveolitis in Crohn's disease. Chest 1985; 87: 363-367.

31. Smiéjan JM, Cosnes J, Chollet-Martin S, et al. Sarcoidlike lymphocytosis of the lower respiratory tract in patients with active Crohn's disease. Ann Intern Med 1986; 104: 17-21.

32. Cormier Y, Bélanger J, Beaudoin J, Laviolette M, Beaudoin R, Herbert J. Abnormal bronchoalveolar lavage in asymptomatic dairy farmers. Study of lymphocytes. $\mathrm{Am}$ Rev Respir Dis 1984; 130: 1046-1049.

33. Cormier Y, Bélanger J, Laviolette M. Persistent bronchoalveolar lymphocytosis in asymptomatic farmers. $\mathrm{Am}$ Rev Respir Dis 1986; 133: 843-847.

34. Constantopoulos SH, Dalavanga YA, Sakellariou K, Goudevenos J, Kotoulas B. Lymphocytic alveolitis and pleural calcifications in nonocupational asbestos exposure. Protection against neoplasia? Am Rev Respir Dis 1992; 146: 1565-1570.

35. Bates DV, ed. Respiratory Function in Disease. 3rd Edn. Philadelphia, W.B. Saunders, 1989; p. 281.

36. Botterman J, Tasson J, Scheltraete K, Pauwels R, Van Der Straeten M, De Schryver A. Scintigraphic, spirometric, and roentgenologic effects of radiotherapy on normal lung tissue. Short-term observation in 14 consecutive patients with breast cancer. Chest 1990; 97: 97-102.

37. Kaufman J, Gunn W, Hartz AJ, et al. The pathophysiologic and roentgenologic effects of chest irradiation in breast carcinoma. Int J Radiation Oncology Biol Phys 1986; 12: 887-893.

38. Rosiello RA, Merril WW. Radiation-induced lung injury. Clin Chest Med 1990; 1: 65-71. 